\title{
ERRATUM
}

\section{Brain repair by hematopoietic growth factors in the subacute phase of traumatic brain injury}

TO THE READERSHIP: An error appeared in the article by Toshkezi et al. (Toshkezi G, Kyle M, Longo SL, et al: Brain repair by hematopoietic growth factors in the subacute phase of traumatic brain injury. $J$ Neurosurg 129:1286-1294, 2018).

In the section Controlled Cortical Impact Model of TBI in the Methods, the contact time was misstated as "85-msec" in the following sentence. The correct contact time is shown below.

A 3-mm flat tip with a strike velocity of $1.5 \mathrm{~m} / \mathrm{sec}$, a 2-mm strike depth from the surface of the dura, and an 8.5-sec contact time was used to induce cortical TBI.

The article has been corrected online as of February $15,2019$.

Li-Ru Zhao, MD, PhD

State University of New York Upstate Medical University, Syracuse, NY

INCLUDE WHEN CITING

Published online February 15, 2019; DOI: 10.3171/2019.1.JNS17878a.

CAANS 2019, except where prohibited by US copyright law 